\title{
Hippocampal TNF-a Signaling Mediates Heroin Withdrawal-Enhanced Fear Learning and Withdrawal-Induced Weight Loss
}

\author{
Shveta V. Parekh ${ }^{1} \cdot$ Jacqueline E. Paniccia ${ }^{1} \cdot$ Lydia O. Adams $^{1} \cdot$ Donald T. Lysle $^{1}$ (D) \\ Received: 6 November 2020 / Accepted: 4 February 2021 / Published online: 13 February 2021 \\ (C) The Author(s) 2021
}

\begin{abstract}
There is significant comorbidity of opioid use disorder (OUD) and post-traumatic stress disorder (PTSD) in clinical populations. However, the neurobiological mechanisms underlying the relationship between chronic opioid use and withdrawal and development of PTSD are poorly understood. Our previous work identified that chronic escalating heroin administration and withdrawal can produce enhanced fear learning, an animal model of hyperarousal, and is associated with an increase in dorsal hippocampal (DH) interleukin-1 $\beta$ (IL-1 $\beta$ ). However, other cytokines, such as TNF- $\alpha$, work synergistically with IL-1 $\beta$ and may have a role in the development of enhanced fear learning. Based on both translational rodent and clinical studies, TNF- $\alpha$ has been implicated in hyperarousal states of PTSD, and has an established role in hippocampal-dependent learning and memory. The first set of experiments tested the hypothesis that chronic heroin administration followed by withdrawal is capable of inducing alterations in DH TNF- $\alpha$ expression. The second set of experiments examined whether DH TNF- $\alpha$ expression is functionally relevant to the development of enhanced fear learning. We identified an increase of TNF- $\alpha$ immunoreactivity and positive cells at 0,24 , and $48 \mathrm{~h}$ into withdrawal in the dentate gyrus DH subregion. Interestingly, intra-DH infusions of etanercept (TNF- $\alpha$ inhibitor) 0,24 , and $48 \mathrm{~h}$ into heroin withdrawal prevented the development of enhanced fear learning and mitigated withdrawal-induced weight loss. Overall, these findings provide insight into the role of TNF- $\alpha$ in opioid withdrawal and the development of anxiety disorders such as PTSD.
\end{abstract}

Keywords Opioid $\cdot$ Withdrawal $\cdot$ Neuroimmune $\cdot$ TNF- $\alpha \cdot$ PTSD $\cdot$ Cytokines

\section{Introduction}

Post-traumatic stress disorder (PTSD), a devastating mental illness, is highly comorbid with substance use disorder (SUD), as nearly $40 \%$ of individuals diagnosed with PTSD are diagnosed with SUD [1]. Specifically, opioid abuse has one of the highest prevalence rates of any comorbid SUD. It has been reported that $33.2 \%$ of individuals with an opioid use disorder (OUD) currently meet criteria for comorbid PTSD and $41 \%$ of those have a lifetime history of PTSD [2, 3]. Notably, comorbidity estimates of heroin use disorder and PTSD are as high as 66\% [4], and this has substantial clinical consequences. Co-occurring PTSD in heroin use disorder is

Donald T. Lysle

dlysle@email.unc.edu

1 Department of Psychology and Neuroscience, University of North Carolina at Chapel Hill, CB\#3270, Chapel Hill, NC 27599-3270, USA associated with an earlier addiction onset age, longer addiction durations, higher rates of attempted suicide, and poorer occupational functioning [4]. Consequently, the mechanisms surrounding this comorbidity present an important area of research in order to improve the treatment, recovery, and outcomes of clinical populations with these psychopathologies.

Heroin use and withdrawal may give rise to long-term neurobiological changes believed to underlie major symptoms of PTSD, such as the fear learning, hyperarousal, and/or reexperiencing events, and increased vulnerability future stressors. Opioid-dependent patients display increased distress on the perceived stress scale, and interestingly, abnormally high cortisol levels have been correlated with an individual's increased discontinuation risk for recovery [5]. Consistent with this, patients undergoing opioid withdrawal have markedly elevated salivary cortisol levels $[6,7]$. These withdrawalinduced physiological effects are pronounced during opioid withdrawal and can have long-lasting consequences [8]. Within the preclinical literature, opioids also have been shown to increase the production of corticotropin-releasing factor 
mRNA [9], and plasma corticosterone levels in rats [10]. The elevated cortisol or corticotropin-releasing factor response associated with opioid use and withdrawal has prominent immune consequences, as it is related to altered cytokine expression in both human and animal models [11-13] and observed across multiple anxiety disorders, such as PTSD [14-17].

Our laboratory has previously shown that dorsal hippocampal (DH) interleukin-1 (IL-1) signaling is responsible for the development of stress-enhanced fear learning (SEFL), a reliable and reproducible animal model of fear-related features of PTSD [18]. Although it is difficult to incorporate all the symptoms of PTSD into a preclinical animal model, SEFL effectively demonstrates hyperarousal and greater susceptibility to future fear learning, a prominent component of human PTSD. In the SEFL paradigm, rats previously exposed to a severe stressor (inescapable foot shocks) show an exaggerated or enhanced fear response to a mild form of stress in a separate, distinct context. The hyperarousal and enhanced reactivity response captured using the enhanced fear learning paradigm offers the opportunity to investigate an important, critical symptom of clinical PTSD. Our laboratory has shown that exposure to the severe stressor in this model induces a time-dependent, region-specific increase in interleukin- $1 \beta$ (IL$1 \beta$ ) immunoreactivity within the dentate gyrus (DG) of the $\mathrm{DH}$ [19]. This stress-induced increase in IL-1 $\beta$ is causally related to enhanced fear learning, as blockade of IL-1 signaling with IL-1 receptor antagonist (IL-1RA) following the severe stressor prevented the development of SEFL [20]. These data suggest that alterations in hippocampal neuroimmune signaling directly lead to maladaptive behavioral responses, such as enhanced fear learning and increased sensitivity to future stressors.

We have recently developed an animal model for chronic escalating heroin administration and withdrawal that we use in combination with the enhanced fear learning paradigm [21]. This model produces reliable withdrawal behaviors such as wet dog shakes, diarrhea, and teeth chattering $24 \mathrm{~h}$ after the last heroin dose. Importantly, this model also produces significant weight loss in heroin-treated animals, a hallmark sign of rodent opioid withdrawal. Strikingly, this model of heroin administration and withdrawal is capable of producing enhanced fear learning and long-lasting hyperarousal [21]. This exciting finding suggests that prolonged opioid exposure and subsequent withdrawal elicit increased stress vulnerability and produce persistent hyperreactivity in a rodent model. In addition to the behavioral consequences, heroin withdrawal induces a similar region-specific increase in IL- $1 \beta$ immunoreactivity within the DG [21]. Critically, intra-DH IL-1RA during heroin withdrawal prevented the development of heroin withdrawal-enhanced fear learning [21]. These studies indicate that the altered DH IL-1 signaling during heroin withdrawal produces long-lasting neuroadaptations that result in exaggerated fear learning behavior.

Although our research has primarily focused on IL- $1 \beta$, central cytokines function in concert to facilitate learning processes [22], and there is evidence that IL-1 $\beta$ does not independently influence heroin withdrawal and enhanced fear learning. Other proinflammatory cytokines, such as TNF- $\alpha$, are critical in learning processes [23], and alter the response to anxiety and distress. Interestingly, the literature suggests that TNF- $\alpha$ and IL- $1 \beta$ have a synergistic relationship in multiple inflammatory mechanisms $[24,25]$, as both cytokines stimulate proinflammatory responses and increase cytokine production. This suggests that the actions of TNF- $\alpha$ and IL- $1 \beta$ are interconnected; however, little is known about the role TNF- $\alpha$ plays in opioid use and withdrawal, as well as the development of hyperarousal states of PTSD. TNF- $\alpha$ has been shown to be upregulated following opioid use [26] and during withdrawal [27]. Likewise, translational evidence from both rodent and clinical studies has implicated TNF- $\alpha$ in stressrelated disorders, such as PTSD [28-30]. Moreover, TNF- $\alpha$ has an integral role in learning and memory processes, as well as cognitive functioning, suggesting a possible role in fear learning behaviors [31-34]. Collectively, these studies support the idea that TNF- $\alpha$ signaling facilitates the ability of chronic heroin administration and withdrawal to enhance future fear learning.

The current studies test the hypothesis that chronic heroin and withdrawal are capable of inducing alterations in TNF- $\alpha$ expression in the DH, and that this DH TNF- $\alpha$ expression is functionally relevant to the development of future enhanced fear learning and withdrawal symptoms, as indicated by weight loss. To this end, experiment 1 determined the consequence of chronic heroin administration and withdrawal on TNF- $\alpha$ expression in the DH. Our analysis focused on the $\mathrm{DH}$ as this region has been shown to be critical to context-dependent fear learning and conditioning [35-37]. Specifically, we focused on the DG subregion, as this is where we observed increased IL- $1 \beta$ expression during heroin withdrawal [21]. We identified increased TNF- $\alpha$ immunoreactivity within the DG following chronic heroin administration 0 , 24 , and $48 \mathrm{~h}$ into withdrawal. Subsequently, experiment 2 tested whether blocking DH TNF- $\alpha$ signaling with etanercept, a TNF- $\alpha$ inhibitor, 0,24 , and $48 \mathrm{~h}$ into heroin withdrawal prevented the development of enhanced fear learning and withdrawal-induced weight loss. We show that etanercept significantly attenuated enhanced fear learning, as well as mitigated withdrawal-induced weight loss. Together, these experiments are the first to test whether DH TNF- $\alpha$ signaling following chronic heroin administration and withdrawal is critical to the development of enhanced future fear learning and mediates other withdrawal-related detriments, such as weight loss.

\section{Methods and Materials}

\section{Animals}

Adult male Sprague Dawley rats (225-250 g, Charles River Laboratories, Raleigh, NC) were individually housed under a reversed 12-h light-dark cycle. Rats were given ad libitum 
access to food and water, and were regularly handled throughout experimentation. All procedures were conducted with approval from the University of North Carolina at Chapel Hill Institutional Animal Care and Use Committee.

\section{Drug Administration}

Heroin (diacetylmorphine hydrochloride, National Institute on Drug Abuse (NIDA) Drug Supply Program, Bethesda, MD, USA) was dissolved in sterile $0.9 \%$ saline to produce $1.0,2.5$, 5.0, 7.5, or $10.0-\mathrm{mg} / \mathrm{mL}$ solutions and stored at $4^{\circ} \mathrm{C}$ until time of injection.

\section{Surgery and Infusion Delivery}

For stereotaxic surgery, animals were anesthetized with a $1.0-\mathrm{mL} / \mathrm{kg}$ intraperitoneal injection of 9:1 (vol $/ \mathrm{vol})$ ketamine hydrochloride $(100 \mathrm{mg} / \mathrm{mL})$ mixed with xylazine $(100 \mathrm{mg} /$ $\mathrm{mL}$ ). Guide cannulae (26 Gauge, Plastics One, 324 Roanoke, VA, USA) were directed bilaterally at the DH 325 ( $\mathrm{AP}-3.4 \mathrm{~mm}, \mathrm{ML} \pm 3.1 \mathrm{~mm}, \mathrm{DV}-2.2 \mathrm{~mm}, 15^{\circ}$, relative to bregma). Animals were given 2 weeks for postoperative recovery prior to the start of experimental procedures. Animals were randomly assigned to receive heroin or saline in the chronic escalating heroin administration and then either a saline or etanercept infusion treatment. Etanercept (Millipore Sigma, St. Louis, MO, USA), a TNF- $\alpha$ inhibitor, was dissolved in sterile saline $(2.5 \mu \mathrm{g} / \mu \mathrm{L})$. Animals underwent the chronic heroin escalating administration and were given three infusions of etanercept or saline at 0,24 , and $48 \mathrm{~h}$ into withdrawal (Standard Infuse/Withdraw PHD 2000 Infusion Syringe Pump, Harvard Apparatus, Holliston, MA, USA). Forty-eight hours prior to the first infusion, animals were given a sham microinjection to allow for habituation to the injection experience. Animals were microinfused with $1.25 \mu \mathrm{g}$ of etanercept or saline vehicle per hemisphere at a rate of 0.25 $\mu \mathrm{L} / \mathrm{min}$, and the injectors were left in place for $1 \mathrm{~min}$ to allow for drug diffusion away from the injection site.

\section{Tissue Collection and Histology}

In experiment 1 , animals were sacrificed by transcardial perfusion $0,24,48$, and $72 \mathrm{~h}$ into withdrawal. Animals that were perfused $1 \mathrm{~h}$ following their last heroin injection were classified to be in the 0 -h withdrawal group, as they were considered to have heroin in their system and, therefore, had not undergone withdrawal. Animals perfused at $24 \mathrm{~h}$ following the last injection are considered to be in the 24-h withdrawal group, while the same applies for the animals perfused at $48 \mathrm{~h}$ and $72 \mathrm{~h}$ groups respectively. Animals were terminally anesthetized with 9:1 ( vol/vol) ketamine hydrochloride $(100 \mathrm{mg} /$ $\mathrm{mL})$ mixed with xylazine $(100 \mathrm{mg} / \mathrm{mL})$, and transcardially perfused with ice-cold phosphate buffer $(\mathrm{PB} ; \mathrm{pH}=7.4)$ followed by $4 \%$ paraformaldehyde in $0.1 \mathrm{M}$ PB. Brains were extracted and post-fixed in $4 \%$ paraformaldehyde for $6 \mathrm{~h}$, and used $30 \%$ sucrose for cryoprotection with $0.1 \%$ sodium azide at $4{ }^{\circ} \mathrm{C}$. Once the brains were saturated with sucrose, brains were cut into $40-\mu \mathrm{m}$ coronal sections on a cryostat (Leica CM 3050 S, Leica Microsystems, Buffalo Grove, IL, USA). For experiment 2 , animals were sacrificed by rapid cervical dislocation and DH cannula placement was verified.

\section{Immunohistochemistry}

Experiment 1 used fluorescent immunohistochemistry (IHC) to examine alterations in DH TNF- $\alpha$ in the DG. The IHC protocol used here has been described previously $[19,21]$. Briefly, tissue sections were washed three times for $10 \mathrm{~min}$ in $0.1 \mathrm{M}$ phosphate buffer $(\mathrm{PB}, \mathrm{pH}=7.4)$, followed by a $1-\mathrm{h}$ incubation in 5\% normal goat serum (NGS) and $0.5 \%$ TritonX100 in 0.1M PB at room temperature. Tissue was incubated in primary antibody:rabbit anti-TNF alpha (1:1000, Abcam, Cambridge, MA, Cat\# ab66579), 5\% NGS, and $0.5 \%$ TritonX100 in $0.1 \mathrm{MPB}$ overnight at $4^{\circ} \mathrm{C}$, washed three times for $10 \mathrm{~min}$ in $0.1 \mathrm{M} \mathrm{PB}$, and incubated in secondary antibody:goat anti-rabbit Alexa Fluor-488 (1:1000, ThermoFisher Scientific, Waltham, MA, Cat \#A11008), 5\% NGS, and $0.5 \%$ TritonX100 in $0.1 \mathrm{M}$ PB for $1 \mathrm{~h}$ at room temperature. Primary antibodies were verified by no primary control stains. Sections were mounted onto SuperFrost Plus slides (Fisher Scientific, Pittsburgh, PA) using Vectashield with DAPI hardset mounting medium (Vector Laboratories, Burlingame, CA).

\section{Microscopy}

Fluorescent microscopy (Leica DM6000 B widefield light microscope, Leica Microsystems, Buffalo Grove, IL, USA) was used to capture color images. Positive fluorescence in images was quantified using automatic Image $J(N I H)$ triangle thresholding feature. The implementation of the ImageJ automatic triangle algorithm has been previously described [38]. Briefly, the algorithm assumes a maximum peak near one end of the histogram and searches for intensity toward the end of the histogram bins. Three to five sections were analyzed bilaterally per animal for the dorsal dentate gyrus and values were averaged and expressed as percent positive stain. In addition, the number of TNF- $\alpha$ positive cells overlaid with DAPI, an indicator of cellular nuclei, in all the images taken was counted manually. All analyses including thresholding and counting were made blind to treatment conditioning. Tissue from two poor perfusions ( $n=10$-h saline and $n=124-\mathrm{h}$ saline) that yielded high nonspecific background which interfered with thresholding was dropped from the analysis. In these perfusions, gross inspection of the brain did not reveal a fixed appearance- - void of blood in circulatory system 
(white to pale yellow color), but instead was found to be reddish, indicative of blood present. Moreover, automatic thresholding failed on this tissue and resulted in exclusion from analysis. The decision to exclude these two samples was made blind to the treatment group. Publication images were compiled with the Adobe Photoshop CS software (Creative Cloud Photoshop v22.1, San Jose, CA, USA). Color levels and background were reduced for optimal representation with level tools. Images from all experimental groups were treated equally.

\section{Chronic Escalating Heroin Administration and Withdrawal}

Animals were randomly assigned to drug (heroin or saline) treatment and heroin withdrawal timepoint $(0,24,48$, or $72 \mathrm{~h}$ ) and underwent chronic escalating heroin administration as described previously [21]. Briefly, rats were injected with heroin or saline 3 times daily (subcutaneous, s.c.) over 24 -h periods for 10 days, with a dose increase every other day: $3.0(3 \times 1.0)$ $\mathrm{mg} / \mathrm{kg} /$ day on days $1-2,7.5(3 \times 2.5) \mathrm{mg} / \mathrm{kg} /$ day on days $3-4$, $15.0(3 \times 5.0) \mathrm{mg} / \mathrm{kg} /$ day on days $5-6,22.5(3 \times 7.5) \mathrm{mg} / \mathrm{kg} /$ day on days $7-8$, and $30(3 \times 10) \mathrm{mg} / \mathrm{kg} /$ day on days 9-10 (Fig. 1a). Animal weights are measured on every dose increase day and subsequent withdrawal timepoints. This chronic escalating and withdrawal paradigm has been shown to robustly produce withdrawal at the 24-h timepoint indicating both dependence of drug and subsequent withdrawal [21, 39].

\section{Chronic Heroin and Withdrawal-Enhanced Fear Learning}

This procedure has been previously described at length [21]. Briefly, animals undergo chronic escalating heroin administration and withdrawal in their home cage. Seven days after the start of withdrawal, animals were placed into a novel context for $15 \mathrm{~min}$ of habituation. On day 8 , animals were placed into the same context for a single scrambled foot shock $(1 \mathrm{~mA}$, $1 \mathrm{~s}$ ) at $3 \mathrm{~min}$ and $12 \mathrm{~s}$. On days 9, 10, 15, and 22 (test days 1, 2, 7 , and 14), animals are placed into the same context for $8 \mathrm{~min}$ and $32 \mathrm{~s}$ and behavior was recorded to measure freezing behavior, a measure of learned fear (Fig. 2a). The Ethovision XT video tracking software (Noldus Information Technology Inc.) was used to analyze freezing behavior. The activity analysis feature (activity threshold $=10$ ) was used to calculate the percent of time each animal was inactive during each contextual fear test and at baseline. Weight was measured at each timepoint to determine withdrawal-induced weight change, as well as infusion-induced weight change (Fig. 3a).

\section{Statistical Analysis}

Experiment 1 was run using separate cohorts for each of the withdrawal timepoints. Therefore, planned comparisons using unpaired, two-tailed Student's $t$ tests determine specifically whether drug treatment altered TNF- $\alpha$ immunoreactivity and cell counts between the $0-\mathrm{h}, 24-\mathrm{h}, 48-\mathrm{h}$, and 72-h timepoints. In experiment 2 , a one-way (heroin, saline) ANOVA was used to analyze baseline freezing data. A 2 (heroin, saline) $\times 2$ (etanercept, saline) $\times 4$ (test day) repeated-measures ANOVA was used to analyze freezing behavior. A 2 (heroin, saline) $\times 2$ (etanercept, saline) $\times 3$ (timepoint) repeatedmeasures ANOVA was used to analyze weight change across withdrawal. Significant interactions for both freezing behavior and weight change were examined using Tukey's post hoc comparisons.

\section{Results}

\section{Experiment 1: Chronic Heroin Administration and Withdrawal Increase TNF-a Immunoreactivity and Positive Cells at 0-h, 24-h, and 48-h Timepoints}

TNF- $\alpha$ immunoreactivity was significantly enhanced by chronic heroin administration and withdrawal in the DG of the DH. TNF- $\alpha$ immunoreactivity was increased during $0-\mathrm{h}$ heroin withdrawal $\left(t_{(18)}=-2.727, p=.029\right)$ (Fig. 1c), 24-h heroin withdrawal $\left(t_{(21)}=-3.416, p=.003\right)$ (Fig. 1d), and 48$\mathrm{h}$ heroin withdrawal $\left(t_{(21)}=-3.190, p=.008\right)$ (Fig. 1e) relative to saline controls, but no difference was observed at 72-h withdrawal $\left(t_{(21)}=-.277, p=-0.603\right)$ (Fig. $\left.1 \mathrm{f}\right)$. Additionally, TNF- $\alpha$ positive cells were significantly enhanced by chronic heroin administration and withdrawal in the DG of the DH. TNF- $\alpha$ positive cells were increased during 0 -h heroin withdrawal $\left(t_{(18)}=12.107, p<.001\right)($ Fig. 1g), 24-h heroin withdrawal $\left(t_{(21)}=-2.542, p=.024\right)$ (Fig. 1h), and 48$\mathrm{h}$ heroin withdrawal $\left(t_{(21)}=5.651, p=.002\right)$ (Fig. 1i) relative to saline controls, but no difference was observed at $72-\mathrm{h}$ withdrawal $\left(t_{(21)}=1.583, p=-0.174\right)($ Fig. $1 \mathrm{j})$. These results show that both a combination of chronic heroin administration and subsequent withdrawal is necessary for increased TNF- $\alpha$ immunoreactivity within the DG as TNF- $\alpha$ immunoreactivity was increased 0,24 , and $48 \mathrm{~h}$ following heroin administration and withdrawal.

\section{Experiment 2: Etanercept (TNF-a Inhibitor) Prevents Chronic Heroin and Withdrawal-Enhanced Fear Learning and Mitigates Withdrawal-Induced Weight Loss}

Intra-DH etanercept prevented enhanced fear learning and mitigated withdrawal-induced weight loss. There was no effect of heroin treatment or etanercept infusion on baseline contextual freezing $\left(F_{(3,25)}=2.216, p=.111\right)$, indicating that there is no generalized fear to the novel context. A $2 \times 2 \times 4$ repeated-measures ANOVA revealed a significant main effect 
a
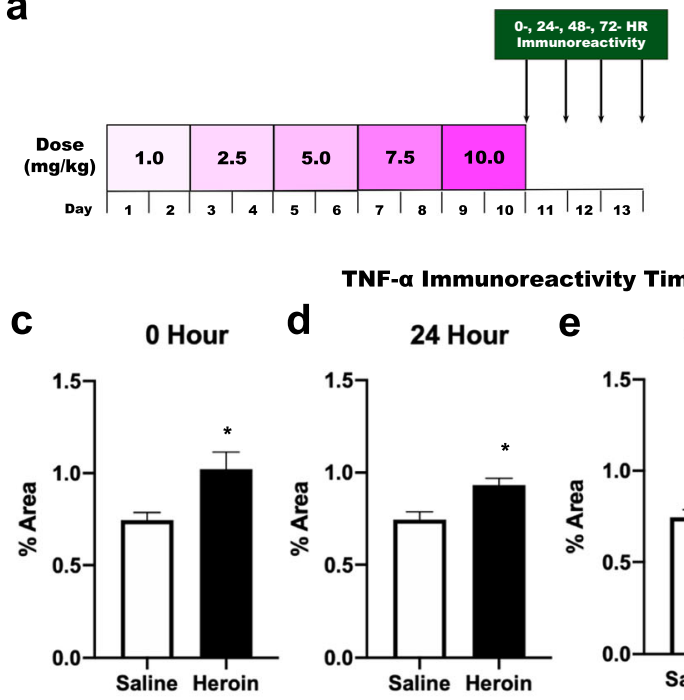

TNF-a Immunoreactivity TimeCourse
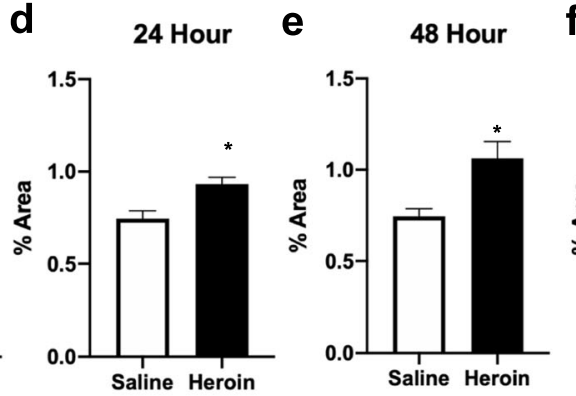

TNF- $\alpha$ Positive Cells TimeCourse

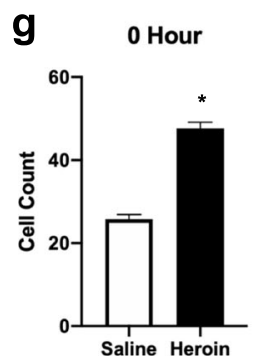

h
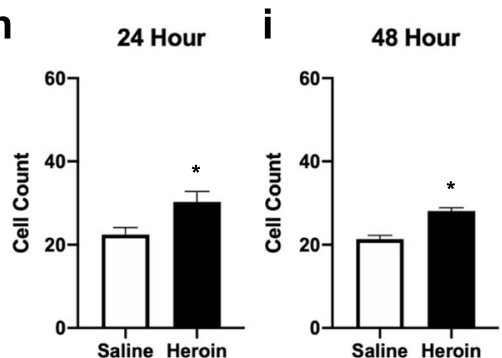

Fig. 1 Chronic heroin administration and withdrawal increase TNF- $\alpha$ in the dentate gyrus of the dorsal hippocampus. Experimental timeline (a). Paxinos and Watson schematic depicting bilateral image acquisition location for the DG of DH (b). Quantification of positive fluorescence

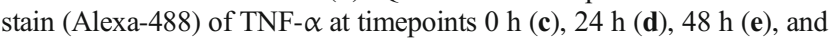
$72 \mathrm{~h}$ (f) into withdrawal $(N=51, n=6-8)$. Quantification of positive cells b

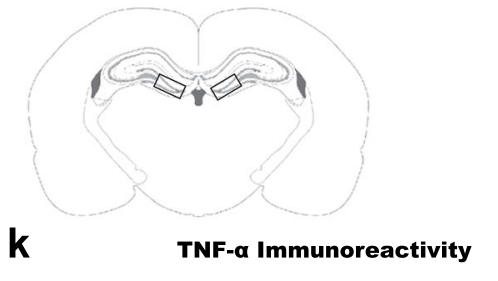

72 Hour
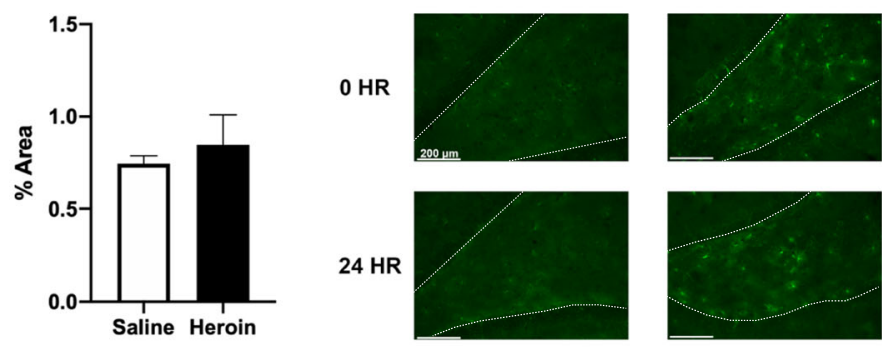

j

72 Hour
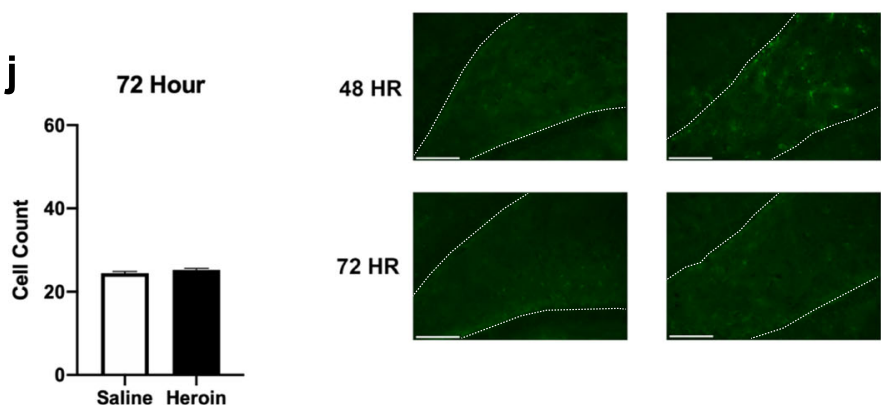

TNF- $\alpha$ at timepoints $0 \mathrm{~h}(\mathbf{g}), 24 \mathrm{~h} \mathrm{(h),} 48 \mathrm{~h}(\mathbf{i})$, and $72 \mathrm{~h} \mathrm{(j)} \mathrm{into}$ withdrawal $(N=51, n=6-8)$. Representative images $(\times 20)$ for saline and heroin animals at all timepoints taken within the DG of the DH. Dotted white lines indicate region of interest $(\mathbf{k})$. *, statistically significant difference relative to respective control. Error bars indicate SEM

control groups $(p>.05)$ (Fig. 2b). These results indicate that intra-DH etanercept during heroin withdrawal prevented future enhanced fear learning.

A $2 \times 2 \times 3$ repeated-measures ANOVA revealed a significant main effect of heroin treatment on withdrawal weight change $\left(F_{(1,25)}=25.410, p<.001\right)$. Weight loss in rodents is a hallmark symptom of opioid withdrawal [40], and may be observed due to increased diarrhea, decreased appetite, or anorexia. Importantly, there was a significant main effect of etanercept treatment on withdrawal weight change $\left(F_{(1,25)}=\right.$ $5.333, p=.029)$ indicating that intra-DH etanercept infusions may have prevented the heroin withdrawal decrease in weight. There was also an overall effect of withdrawal time $\left(F_{(2,50)}=\right.$ $41.192, p<.001)$, indicating over the course of withdrawal animals started to gain weight again (Fig. 3b).

Tukey's post hoc comparisons revealed during the 24-h withdrawal timepoint, both the saline control groups did not differ in weight change $(p>.05)$. Importantly, heroin-withdrawn, vehicle-treated animals had a significantly higher weight change compared to both the saline control groups $(p$ 
a

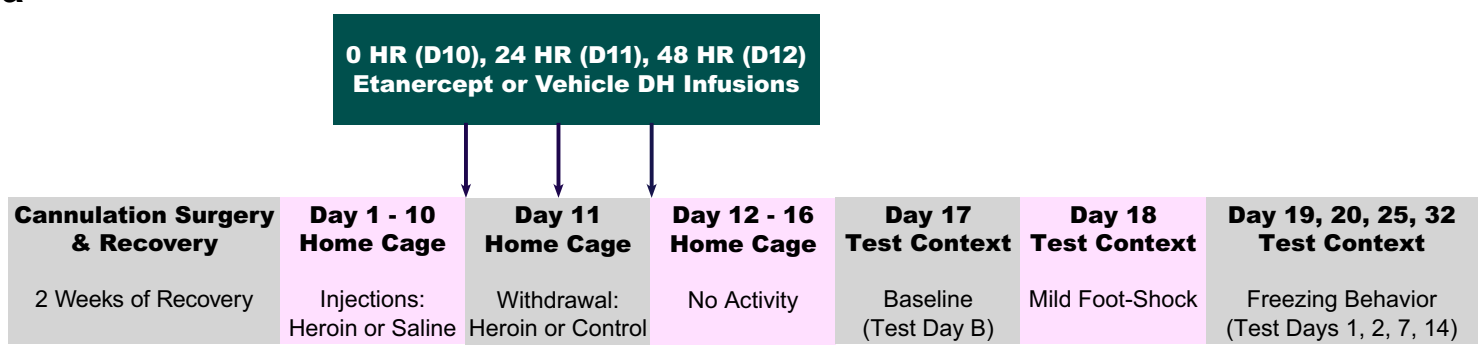

b

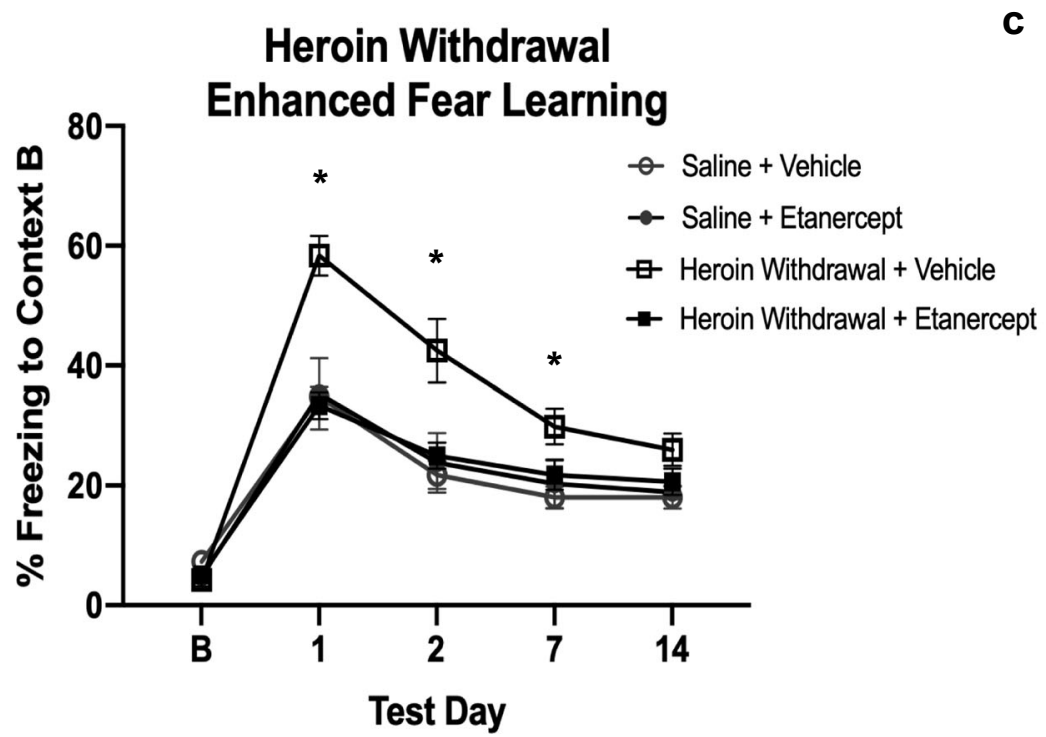

C

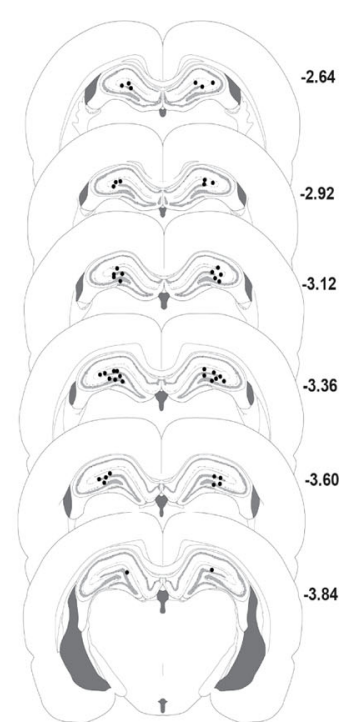

Fig. 2 Etanercept (TNF- $\alpha$ inhibitor) prevents the development of heroin withdrawal-enhanced fear learning. Experimental timeline (a). Intra-DH etanercept infusions significantly attenuated enhanced fear learning $(N=$ $31, n=6-9$ ) (b). Paxinos and Watson schematic with DH cannula

$<.001$ ) and heroin-withdrawn, etanercept-treated animals also had a significantly higher weight change compared to both the saline control groups $(p<.001)$. Strikingly, heroin-withdrawal, vehicle-treated animals had a significantly higher weight change in comparison to heroin-withdrawn, etanercept-treated animals $(p<.05)$, indicating that etanercept treatment mitigated the withdrawal-induced weight loss at 24-h withdrawal (Fig. 3b).

Similarly, during the 48-h withdrawal timepoint, Tukey's post hoc comparisons revealed both the saline control groups did not differ in weight change $(p>.05)$. Importantly, heroinwithdrawn, vehicle-treated animals had a significantly higher weight change compared to both the saline control groups $(p<$ $.001)$ and heroin-withdrawn, etanercept-treated animals also had a significantly higher weight change compared to both the saline control groups $(p<.001)$. Strikingly, heroin-withdrawn, vehicle-treated animals had a significantly higher weight change in comparison to heroin-withdrawn, etanercepttreated animals $(p<.05)$, indicating that etanercept treatment mitigated the withdrawal-induced weight throughout the 48-h withdrawal timepoint. During the 72-h withdrawal timepoint, placements shown. Each circle represents termination site of the cannula tract $(\mathbf{c})$. *, statistically significant difference relative to respective control. Error bars indicate SEM

both the saline control groups did not differ in weight change ( $p>.05$ ), and heroin-withdrawn, vehicle-treated animals had a significantly higher weight change compared to both the saline control groups $(p<.001)$ (Fig. 3b). Overall, these results show that the etanercept was able to prevent enhanced fear learning, as well as mitigate heroin withdrawal-induced weight loss.

\section{Discussion}

The current study demonstrates for the first time that $\mathrm{DH}$ TNF- $\alpha$ signaling mediates some long-lasting maladaptive behavioral responses induced by chronic heroin and withdrawal. We have shown that exposure to chronic heroin administration and withdrawal induces TNF- $\alpha$ immunoreactivity and TNF- $\alpha$ positive cell counts within the DG, and disrupting DH TNF- $\alpha$ signaling during withdrawal blocks the development of enhanced fear learning. Critically, this manipulation also mitigates heroin withdrawal-induced weight loss, a hallmark sign of withdrawal in rodent models. These findings 
Fig. 3 Etanercept (TNF- $\alpha$ inhibitor) mitigates the heroin withdrawal-induced weight loss. Experimental timeline (a). IntraDH etanercept infusions significantly reduced the withdrawal-induced weight loss $(N=31, n=6-9)(\mathbf{b})$. Cannula placements can be seen in Fig. 2c. *, statistically significant difference as indicated by bars. Error bars indicate SEM a

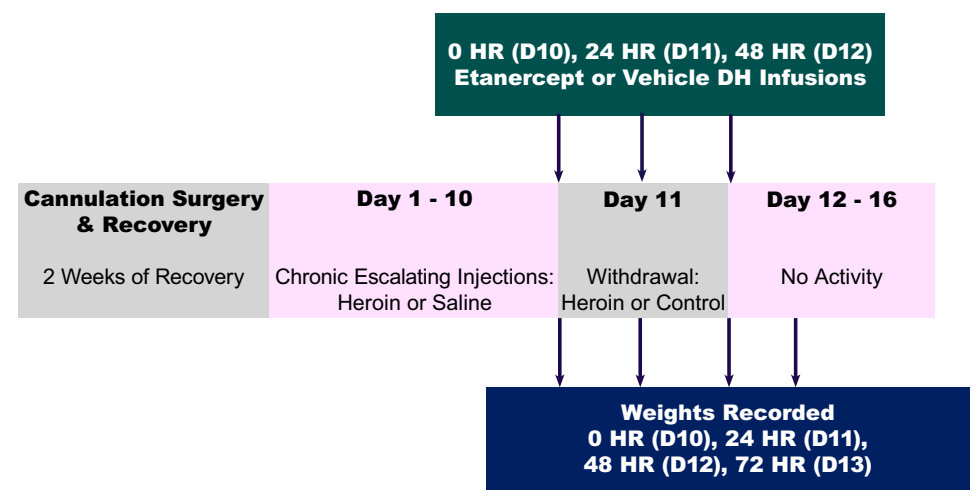

b Weight Change Across Heroin Withdrawal

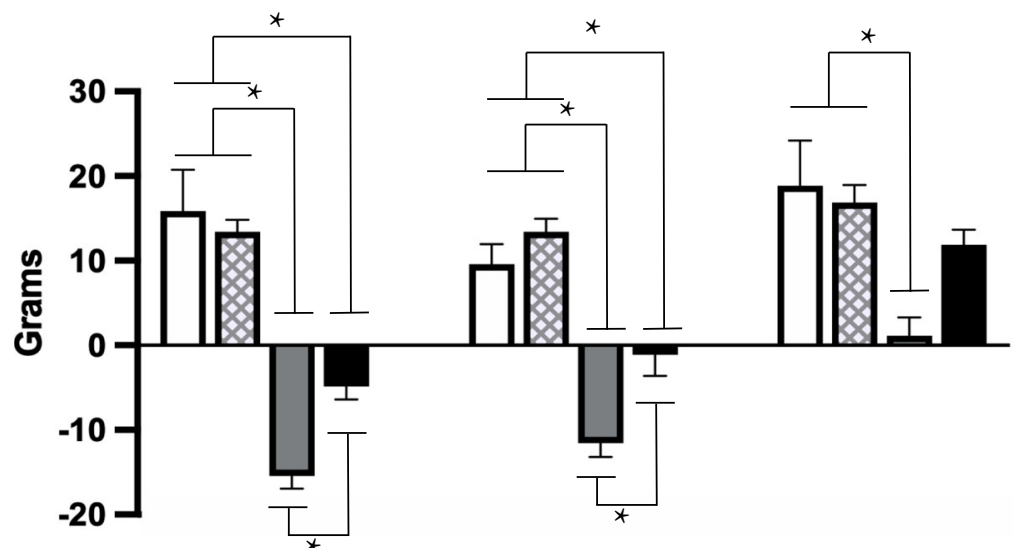

24 Hour

48 Hour

72 Hour

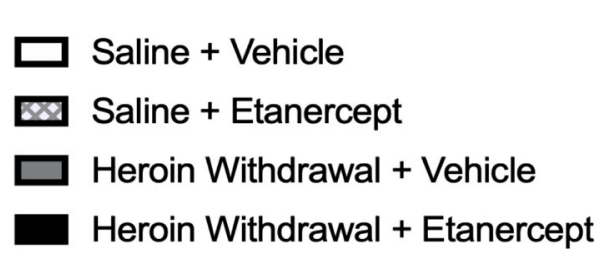

provide new evidence that heroin withdrawal-induced TNF- $\alpha$ is necessary for the development of future enhanced fear learning and is a potential mechanism by which opioids and opioid withdrawal can elicit fear-related and arousal-related features of PTSD symptomatology.

The present findings suggest that neurobiological changes, specifically increases in TNF- $\alpha$ immunoreactivity, leave the animals hypersensitive to future stressors. Exposure to chronic heroin administration and withdrawal increases TNF- $\alpha$ immunoreactivity within the DG up to $48 \mathrm{~h}$ into withdrawal. This finding complements our recently published IL-1 findings [21]; however, IL-1 was only seen to be upregulated during the 24-h withdrawal period. The current experiments demonstrate both chronic heroin administration and withdrawal increase TNF- $\alpha$ immunoreactivity, as TNF- $\alpha$ was also increased at the non-withdrawal 0 -h timepoint. This suggests TNF- $\alpha$ levels may elevate at some point during chronic, escalating heroin administration and persists well into the withdrawal period. This is consistent with the literature, as TNF- $\alpha$ is elevated following morphine use and withdrawal [41-43], naloxone-precipitated opioid withdrawal [44], and morphine withdrawal-driven synaptic plasticity [45]. These opioidrelated neuroimmune alterations can lead to long-lasting neural adaptations and increase vulnerability to health detriments, such as anxiety disorders, associated with use [46-48]. The current experiments establish that TNF- $\alpha$ signaling is critical 
to the learning processes resulting in the formation of a maladaptive behavioral phenotype following heroin use and withdrawal.

The present study demonstrates that heroin and withdrawalinduced enhanced fear learning is driven by hippocampal TNF- $\alpha$ signaling, as inhibiting DH TNF- $\alpha$ signaling disrupts future exaggerated fear conditioning. A significant body of literature implicates TNF- $\alpha$ signaling as an integral component of the learning and memory processes. Specifically, a local increase of TNF- $\alpha$ in the hippocampal dentate gyrus activates TNF receptor type 1 , which triggers an astrocyte-neuron signaling cascade resulting in persistent functional modification of hippocampal excitatory synapses [33]. Moreover, TNF- $\alpha$ modulates hippocampal synapses via AMPA receptor trafficking and $\mathrm{GABA}_{\mathrm{A}}$ receptors $[49,50]$. This suggests that TNF- $\alpha$ is a key physiological regulator of hippocampal synaptic activity and excessive TNF- $\alpha$ may alter synaptic functioning and learning mechanisms, potentially impacting the development of enhanced fear learning. Specifically, the current studies suggest that blocking the TNF- $\alpha$ increase reduced conditioned freezing behaviors, suggesting an attenuation of enhanced fear learning. Consistent with this, studies have shown that increases in TNF- $\alpha$ are necessary for sustained fear learning, both in cued and contextual acquisition and extinction [33, 51], and inhibiting TNF- $\alpha$ reduces memory deterioration induced by LPS [32]. These studies as well as the present work suggest that TNF- $\alpha$ signaling plays a critical role in learning and memory processes.

The focus of the current work examined the role of hippocampal TNF- $\alpha$ in heroin withdrawal for enhanced fear learning and weight loss, and directly compliments our previous work indicating that IL-1 signaling is involved in heroin withdrawal and enhanced fear learning [21]. Evidence suggests that IL- $1 \beta$ 's effects may be a result of synergistic interaction with TNF- $\alpha$ [52]. The interdependent relationship between IL- $1 \beta$ and TNF- $\alpha$ has been demonstrated in multiple models, such that TNF- $\alpha$ action promotes additional TNF- $\alpha$ transcription, as well as the production and release of IL-1 $\beta[53,54]$. Additionally, both the TNF- $\alpha$ and IL-1 signaling pathways lead to the activation of the proinflammatory transcription factor, NF-KB [55-57], suggesting that these cytokines work together in multiple neuroinflammatory processes. Studies to examine the interaction between IL-1 and TNF- $\alpha$ signaling in heroin withdrawal-enhanced fear learning would provide more information regarding the long-lasting neuroimmune adaptations driving this behavioral effect.

Evidence suggests that glial activation leads to the release of proinflammatory molecules that modulate neuronal activity crucial to the complex syndrome of opioid dependence and withdrawal. In particular, glial cells appear to be primarily responsible for TNF- $\alpha$ release [58], which may be mediated through glutamate release from astrocytes and microglia [59]. Studies have shown that astrocyte-derived TNF- $\alpha$ may alter hippocampal synapses and modify excitatory synapses [33], while microglial production of TNF- $\alpha$ has been implicated as a key element of sustained fear memory [51]. Additionally, high levels of TNF- $\alpha$ can signal astrocytes and microglia via activation of NF-KB to elicit a proinflammatory response which increases production of a large number of other cytokines, such as IL-1 [57, 60, 61]. Cell-specific studies on both microglia and astrocytes may increase our understanding to the origin of TNF- $\alpha$ in our model, as well as its mechanism in heroin use and withdrawal to alter future learning and memory processes. Future studies can extend this line of work to examine the cellular source and targets of this TNF- $\alpha$ signaling, as well as the role of glia in modulating exaggerated fear learning responses.

The present work focused on the $\mathrm{DH}$, a brain region critical to learning and memory processes. As disruption of TNF- $\alpha$ signaling mitigated withdrawal-induced weight loss, future studies should investigate TNF- $\alpha$ expression in other areas involved in opioid abuse, such as the ventral tegmental area, locus coeruleus, or periaqueductal gray (PAG). Specifically, the PAG can be targeted to better understand the effects of TNF- $\alpha$ in heroin withdrawal and withdrawal symptomology. Functional studies have implicated the PAG in the expression of symptoms of opioid withdrawal, but the molecular mechanisms involved are not fully understood. Further studies should investigate the role of TNF- $\alpha$ expression in other brain regions involved in opioid abuse, such as the PAG, that may also contribute to enhance fear learning and alter heroin withdrawal-induced weight loss or other withdrawal-related behaviors.

Strikingly, intra-DH etanercept infusions mitigated heroin withdrawal-induced weight loss. This intriguing finding demonstrates a role for DH TNF- $\alpha$ signaling in both learning processes and withdrawal behaviors, such as weight loss. Although this study evaluated weight loss and freezing behavior separately, it would be interesting to study the correlation between these two behaviors. As regards to weight loss, specifically, we believe TNF- $\alpha$ may be exerting an anorexic effect in opposition to ghrelin. Studies have shown that lower levels of total TNF- $\alpha$ promoter methylation had higher success with a weight loss program [62], and therefore the dysregulation of TNF- $\alpha$ following heroin use and withdrawal may contribute to the weight loss associated with withdrawal. Although the current study focused solely on weight loss, as it is a prominent symptom of rodent opioid withdrawal, it would be interesting to investigate TNF- $\alpha$ 's effect on other withdrawal behaviors such as wet dog shakes, teeth chattering, and diarrhea. It is possible that these behaviors may also be mediated by TNF- $\alpha$ signaling, as it has been previously shown that downregulating TNF- $\alpha$ signaling in the periaqueductal gray (PAG) of mice decreased the physical symptoms of morphine withdrawal [63]. In particular, studies have shown that heroin administration can directly stimulate glial toll-like receptor 4 (TLR4) that results in the 
overexpression of TNF- $\alpha$ and injection of TNF- $\alpha$ into the PAG produces withdrawal symptoms [64]. This suggests TNF- $\alpha$ regulates symptoms of opioid withdrawal and inhibition can mitigate these effects. Further studies can investigate the effect of region-specific infusions of etanercept on other symptoms of opioid withdrawal. In line with our current findings, we hypothesize that systemic etanercept or peripheral administration would decrease other behaviors of heroin withdrawal. Unfortunately, biologic TNF inhibitors, such as etanercept, do not cross the blood-brain barrier (BBB) [65]. TNF inhibitors have been engineered to penetrate the BBB in combination with a transgenic mouse line through the fusion of extracellular domain of the type II human TNF receptor to a chimeric monoclonal antibody designed to function as a fusion protein [66]. Further studies can study the peripheral effect of TNF inhibitors on heroin withdrawal behaviors using the novel engineered TNF inhibitors. We hypothesize that given systemically, novel engineered TNF inhibitors may ameliorate other physical symptoms of withdrawal as the delivered inhibitor will reach multiple brain regions as well as peripheral processes.

In summary, our exciting findings demonstrate that heroin use and withdrawal increase expression of hippocampal TNF- $\alpha$, and inhibition of TNF- $\alpha$ signaling disrupts future enhanced fear learning, as well as mitigates heroin withdrawal-induced weight loss. Collectively, these data provide important new evidence that chronic heroin administration and withdrawal alter hippocampal neuroimmune signaling and downstream behavioral responses, such as enhanced susceptibility to future stressors and withdrawal-induced weight loss. The current study identifies neuroimmune targets that can be used to alleviate long-term maladaptive responses stemming from a history of chronic heroin use and protracted withdrawal.

\begin{abstract}
Author Contribution SVP led the conception, design, and conduction of experiments, data collection and analysis, and drafting, revision, and submission of the manuscript. DTL and JEP significantly contributed to the design and conduction of experiments, data interpretation, and critical revisions of the manuscript. LOA significantly contributed to the critical editorial and intellectual revisions to the manuscript.
\end{abstract}

Funding This research was supported by the National Institute on Drug Abuse (NIDA) grants T32 DA007244 (SVP, JEP), R01 DA034721 (DTL), R21 DA048241 (DTL), and F31 DA047054 (JEP).

Data Availability The datasets that support the findings of this study are available from the corresponding author upon reasonable request.

Code Availability Not applicable.

\section{Declarations}

Consent to Participate Not applicable.
Consent to Publish Not applicable.

Conflict of Interest The authors declare no competing interests.

Animal Experiments All procedures were conducted in accordance with the National Institutes of Health guide for care and use of laboratory animals and with approval from the University of North Carolina at Chapel Hill Institutional Animal Care and Use Committee. All efforts were made to minimize animal suffering, reduce the number of animals used, and utilize alternatives to in vivo techniques, when available.

Open Access This article is licensed under a Creative Commons Attribution 4.0 International License, which permits use, sharing, adaptation, distribution and reproduction in any medium or format, as long as you give appropriate credit to the original author(s) and the source, provide a link to the Creative Commons licence, and indicate if changes were made. The images or other third party material in this article are included in the article's Creative Commons licence, unless indicated otherwise in a credit line to the material. If material is not included in the article's Creative Commons licence and your intended use is not permitted by statutory regulation or exceeds the permitted use, you will need to obtain permission directly from the copyright holder. To view a copy of this licence, visit http://creativecommons.org/licenses/by/4.0/.

\section{References}

1. Mills KL, Teesson M, Ross J, Peters L (2006) Trauma, PTSD, and substance use disorders: findings from the Australian National Survey of Mental Health and Well-Being. Am J Psychiatry. 163(4):652-658. https://doi.org/10.1176/appi.ajp.163.4.652

2. Saha TD, Kerridge BT, Goldstein RB, Chou SP, Zhang H, Jung J, Pickering RP, Ruan WJ et al (2016) Nonmedical prescription opioid use and DSM-5 nonmedical prescription opioid use disorder in the United States. J Clin Psychiatry. 77(6):772-780. https://doi.org/ 10.4088/JCP. $15 \mathrm{~m} 10386$

3. Dahlby L, Kerr T (2020) PTSD and opioid use: implications for intervention and policy. Subst Abuse Treat Prev Policy. 15(1):22. https://doi.org/10.1186/s13011-020-00264-8

4. Mills KL, Marel C, Darke S, Ross J, Slade T, Teesson M (2018) The long-term impact of post traumatic stress disorder on recovery from heroin dependence. J Subst Abuse Treat. 89:60-66. https:// doi.org/10.1016/j.jsat.2018.04.001

5. Jaremko KM, Sterling RC, Van Bockstaele EJ (2015) Psychological and physiological stress negatively impacts early engagement and retention of opioid-dependent individuals on methadone maintenance. J Subst Abuse Treat. 48(1):117-127. https://doi.org/10.1016/j.jsat.2014.08.006

6. Zhang GF, Ren YP, Sheng LX, Chi Y, Du WJ, Guo S, Jiang ZN, Xiao L et al (2008) Dysfunction of the hypothalamic-pituitaryadrenal axis in opioid dependent subjects: effects of acute and protracted abstinence. Am J Drug Alcohol Abuse. 34(6):760-768. https://oi.org/10.1080/00952990802385781

7. Cami J, Gilabert M, San L, de la Torre R (1992) Hypercortisolism after opioid discontinuation in rapid detoxification of heroin addicts. Br J Addict. 87(8):1145-1151. https://doi.org/10.1111/j. 1360-0443.1992.tb02001.x

8. Bearn J, Buntwal N, Papadopoulos A, Checkley S (2001) Salivary cortisol during opiate dependence and withdrawal. Addict Biol. 6(2):157-162. https://doi.org/10.1080/13556210020040235

9. Houshyar H, Gomez F, Manalo S, Bhargava A, Dallman MF (2003) Intermittent morphine administration induces dependence 
and is a chronic stressor in rats. Neuropsychopharmacology. 28(11):1960-1972. https://doi.org/10.1038/sj.npp.1300271

10. McNally GP, Akil H (2002) Role of corticotropin-releasing hormone in the amygdala and bed nucleus of the stria terminalis in the behavioral, pain modulatory, and endocrine consequences of opiate withdrawal. Neuroscience. 112(3):605-617. https://doi.org/ 10.1016/s0306-4522(02)00105-7

11. Lashkarizadeh MR, Garshasbi M, Shabani M, Dabiri S, Hadavi H, Manafi-Anari H (2016) Impact of opium addiction on levels of proand anti-inflammatory cytokines after surgery. Addict Health. 8(1): 9-15

12. O’Sullivan SJ, Malahias E, Park J, Srivastava A, Reyes BAS, Gorky J, Vadigepalli R, Van Bockstaele EJ et al (2019) Singlecell glia and neuron gene expression in the central amygdala in opioid withdrawal suggests inflammation with correlated gut dysbiosis. Front Neurosci. 13:665. https://doi.org/10.3389/fnins. 2019.00665

13. Wang TY, Lee SY, Chang YH, Chen SL, Chen PS, Chu CH, Huang SY, Tzeng NS et al (2018) Correlation of cytokines, BDNF levels, and memory function in patients with opioid use disorder undergoing methadone maintenance treatment. Drug Alcohol Depend. 191:6-13. https://doi.org/10.1016/j.drugalcdep. 2018.06.024

14. Kim TD, Lee S, Yoon S (2020) Inflammation in post-traumatic stress disorder (PTSD): a review of potential correlates of PTSD with a neurological perspective. Antioxidants (Basel). 9(2). https:// doi.org/10.3390/antiox9020107

15. Hori H, Kim Y (2019) Inflammation and post-traumatic stress disorder. Psychiatry Clin Neurosci. 73(4):143-153. https://doi.org/10. 1111/pen. 12820

16. Gola H, Engler H, Sommershof A, Adenauer H, Kolassa S, Schedlowski M, Groettrup M, Elbert T et al (2013) Posttraumatic stress disorder is associated with an enhanced spontaneous production of pro-inflammatory cytokines by peripheral blood mononuclear cells. BMC psychiatry. 13:40. https://doi.org/10.1186/1471244X-13-40

17. Corline J, Brouwers JMW, von Kanel R (2015) Inflammatory markers in PTSD. In: Comprehensive guide to post-traumatic stress disorder. Springer, Cham. https://doi.org/10.1007/978-3-31908613-2_54-1

18. Rau V, DeCola JP, Fanselow MS (2005) Stress-induced enhancement of fear learning: an animal model of posttraumatic stress disorder. Neurosci Biobehav Rev. 29(8):1207-1223. https://doi.org/ 10.1016/j.neubiorev.2005.04.010

19. Jones ME, Lebonville CL, Barrus D, Lysle DT (2015) The role of brain interleukin-1 in stress-enhanced fear learning. Neuropsychopharmacology. 40(5):1289-1296. https://doi.org/10. 1038/npp.2014.317

20. Jones ME, Lebonville CL, Paniccia JE, Balentine ME, Reissner KJ, Lysle DT (2017) Hippocampal interleukin-1 mediates stressenhanced fear learning: a potential role for astrocyte-derived interleukin-1 $\beta$. Brain Behav Immun 67:355-363. https://doi.org/10. 1016/j.bbi.2017.09.016

21. Parekh SV, Paniccia JE, Lebonville CL, Lysle DT (2020) Dorsal hippocampal interleukin-1 signaling mediates heroin withdrawalenhanced fear learning. Psychopharmacology (Berl). 237:36533664. https://doi.org/10.1007/s00213-020-05645-2

22. Yirmiya R, Goshen I (2011) Immune modulation of learning, memory, neural plasticity and neurogenesis. Brain Behav Immun. 25(2): 181-213. https://doi.org/10.1016/j.bbi.2010.10.015

23. Santello M, Volterra A (2012) TNF $\alpha$ in synaptic function: switching gears. Trends Neurosci 35(10):638-647. https://doi.org/ 10.1016/j.tins.2012.06.001

24. Kucharzik T, Lugering N, Adolf M, Domschke W, Stoll R (1997) Synergistic effect of immunoregulatory cytokines on peripheral blood monocytes from patients with inflammatory bowel disease.
Dig Dis Sci. 42(4):805-812. https://doi.org/10.1023/a: 1018872332387

25. Martensson K, Chrysis D, Savendahl L (2004) Interleukin-1beta and TNF-alpha act in synergy to inhibit longitudinal growth in fetal rat metatarsal bones. J Bone Miner Res. 19(11):1805-1812. https:// doi.org/10.1359/JBMR.040805

26. Amri J, Sadegh M, Moulaei N, Palizvan MR (2018) Transgenerational modification of hippocampus TNF-alpha and S100B levels in the offspring of rats chronically exposed to morphine during adolescence. Am J Drug Alcohol Abuse. 44(1):95102. https://doi.org/10.1080/00952990.2017.1348509

27. Mansouri MT, Naghizadeh B, Ghorbanzadeh B, Amirgholami N, Houshmand G, Alboghobeish S (2020) Venlafaxine inhibits naloxone-precipitated morphine withdrawal symptoms: role of inflammatory cytokines and nitric oxide. Metab Brain Dis. 35(2): 305-313. https://doi.org/10.1007/s11011-019-00491-4

28. Liu YN, Peng YL, Liu L, Wu TY, Zhang Y, Lian YJ, Yang YY, Kelley KW et al (2015) TNFalpha mediates stress-induced depression by upregulating indoleamine 2,3-dioxygenase in a mouse model of unpredictable chronic mild stress. Eur Cytokine Netw. 26(1):15-25. https://doi.org/10.1684/ecn.2015.0362

29. Hussein S, Dalton B, Willmund GD, Ibrahim MAA, Himmerich $H$ (2017) A systematic review of tumor necrosis factor-alpha in posttraumatic stress disorder: evidence from human and animal studies. Psychiatr Danub 29(4):407-420. https://doi.org/10.24869/psyd. 2017.407

30. Zass LJ, Hart SA, Seedat S, Hemmings SM, Malan-Muller S (2017) Neuroinflammatory genes associated with post-traumatic stress disorder: implications for comorbidity. Psychiatr Genet. 27(1):1-16. https://doi.org/10.1097/YPG.0000000000000143

31. Ma X, Fang F, Song M, Ma S (2015) The effect of isoliquiritigenin on learning and memory impairments induced by high-fat diet via inhibiting TNF-alpha/JNK/IRS signaling. Biochem Biophys Res Commun. 464(4):1090-1095. https://doi.org/10.1016/j.bbrc.2015. 07.081

32. Noorbakhshnia M, Karimi-Zandi L (2017) Portulaca oleracea L. prevents lipopolysaccharide-induced passive avoidance learning and memory and TNF-alpha impairments in hippocampus of rat. Physiol Behav. 169:69-73. https://doi.org/10.1016/j.physbeh. 2016.11.027

33. Habbas S, Santello M, Becker D, Stubbe H, Zappia G, Liaudet N, Klaus FR, Kollias G et al (2015) Neuroinflammatory TNFalpha impairs memory via astrocyte signaling. Cell 163(7):1730-1741. https://doi.org/10.1016/j.cell.2015.11.023

34. Camara ML, Corrigan F, Jaehne EJ, Jawahar MC, Anscomb H, Koerner H, Baune BT (2013) TNF-alpha and its receptors modulate complex behaviours and neurotrophins in transgenic mice. Psychoneuroendocrinology. 38(12):3102-3114. https://doi.org/10. 1016/j.psyneuen.2013.09.010

35. Huckleberry KA, Shue F, Copeland T, Chitwood RA, Yin W, Drew MR (2018) Dorsal and ventral hippocampal adult-born neurons contribute to context fear memory. Neuropsychopharmacology. 43(12):2487-2496. https://doi.org/10.1038/s41386-018-0109-6

36. Anagnostaras SG, Gale GD, Fanselow MS (2001) Hippocampus and contextual fear conditioning: recent controversies and advances. Hippocampus 11(1):8-17. https://doi.org/10.1002/10981063(2001)11:1<8::AID-HIPO1015>3.0.CO;2-7

37. Acheson DT, Gresack JE, Risbrough VB (2012) Hippocampal dysfunction effects on context memory: possible etiology for posttraumatic stress disorder. Neuropharmacology. 62(2):674-685. https:// doi.org/10.1016/j.neuropharm.2011.04.029

38. Zack GW, Rogers WE, Latt SA (1977) Automatic measurement of sister chromatid exchange frequency. J Histochem Cytochem. 25(7):741-753. https://doi.org/10.1177/25.7.70454

39. Zhou Y, Leri F, Ho A, Kreek MJ (2013) Suppression of hypothalamic-pituitary-adrenal axis by acute heroin challenge in 
rats during acute and chronic withdrawal from chronic heroin administration. Neurochem Res. 38(9):1850-1860. https://doi.org/ 10.1007/s11064-013-1091-3

40. Gellert VF, Holtzman SG (1978) Development and maintenance of morphine tolerance and dependence in the rat by scheduled access to morphine drinking solutions. J Pharmacol Exp Ther. 205(3): 536-546

41. Doyle HH, Eidson LN, Sinkiewicz DM, Murphy AZ (2017) Sex differences in microglia activity within the periaqueductal gray of the rat: a potential mechanism driving the dimorphic effects of morphine. J Neurosci. 37(12):3202-3214. https://doi.org/10.1523/ JNEUROSCI.2906-16.2017

42. Doyle HH, Murphy AZ (2018) Sex-dependent influences of morphine and its metabolites on pain sensitivity in the rat. Physiol Behav. 187:32-41. https://doi.org/10.1016/j.physbeh.2017.11.030

43. Eidson LN, Inoue K, Young LJ, Tansey MG, Murphy AZ (2017) Toll-like receptor 4 mediates morphine-induced neuroinflammation and tolerance via soluble tumor necrosis factor signaling. Neuropsychopharmacology. 42(3):661-670. https://doi.org/10. 1038/npp.2016.131

44. Xiang H, Tian Y, Sun Y (2005) Effect of morphine and naloxone on release of the excitatory amino acids of spinal astrocytes induced by TNF-alpha. J Huazhong Univ Sci Technolog Med Sci. 25(1): 91-93. https://doi.org/10.1007/BF02831397

45. Valentinova K, Tchenio A, Trusel M, Clerke JA, Lalive AL, Tzanoulinou S, Matera A, Moutkine I et al (2019) Morphine withdrawal recruits lateral habenula cytokine signaling to reduce synaptic excitation and sociability. Nat Neurosci. 22(7):1053-1056. https://doi.org/10.1038/s41593-019-0421-4

46. Hutchinson MR, Northcutt AL, Chao LW, Kearney JJ, Zhang Y, Berkelhammer DL, Loram LC, Rozeske RR et al (2008) Minocycline suppresses morphine-induced respiratory depression, suppresses morphine-induced reward, and enhances systemic morphine-induced analgesia. Brain Behav Immun. 22(8):12481256. https://doi.org/10.1016/j.bbi.2008.07.008

47. Hutchinson MR, Coats BD, Lewis SS, Zhang Y, Sprunger DB, Rezvani N, Baker EM, Jekich BM et al (2008) Proinflammatory cytokines oppose opioid-induced acute and chronic analgesia. Brain Behav Immun. 22(8):1178-1189. https://doi.org/10.1016/j. bbi.2008.05.004

48. Hutchinson MR, Lewis SS, Coats BD, Skyba DA, Crysdale NY, Berkelhammer DL, Brzeski A, Northcutt A et al (2009) Reduction of opioid withdrawal and potentiation of acute opioid analgesia by systemic AV411 (ibudilast). Brain Behav Immun. 23(2):240-250. https://doi.org/10.1016/j.bbi.2008.09.012

49. Beattie EC, Stellwagen D, Morishita W, Bresnahan JC, Ha BK, Von Zastrow M, Beattie MS, Malenka RC (2002) Control of synaptic strength by glial TNFalpha. Science. 295(5563):2282-2285. https://doi.org/10.1126/science.1067859

50. Pribiag H, Stellwagen D (2013) TNF-alpha downregulates inhibitory neurotransmission through protein phosphatase 1-dependent trafficking of GABA(A) receptors. J Neurosci. 33(40):1587915893. https://doi.org/10.1523/JNEUROSCI.0530-13.2013

51. Yu Z, Fukushima H, Ono C, Sakai M, Kasahara Y, Kikuchi Y, Gunawansa N, Takahashi Y et al (2017) Microglial production of TNF-alpha is a key element of sustained fear memory. Brain Behav Immun. 59:313-321. https://doi.org/10.1016/j.bbi.2016.08.011

52. McGee DW, Bamberg T, Vitkus SJ, McGhee JR (1995) A synergistic relationship between TNF-alpha, IL-1 beta, and TGF-beta 1 on IL-6 secretion by the IEC-6 intestinal epithelial cell line. Immunology. 86(1):6-11

53. Hoffmann G, Schloesser M, Czechowski M, Schobersberger W, Furhapter C, Sepp N (2004) Tumor necrosis factor-alpha gene expression and release in cultured human dermal microvascular endothelial cells. Exp Dermatol. 13(2):113-119. https://doi.org/ 10.1111/j.0906-6705.2004.00142.x

54. Haddad JJ (2002) Recombinant TNF-alpha mediated regulation of the I kappa B-alpha/NF-kappa B signaling pathway: evidence for the enhancement of pro- and anti-inflammatory cytokines in alveolar epithelial cells. Cytokine 17(6):301-310. https://doi.org/10. 1006/cyto.2002.1017

55. Rex J, Lutz A, Faletti LE, Albrecht U, Thomas M, Bode JG, Borner C, Sawodny O et al (2019) IL-1beta and TNFalpha differentially influence NF-kappaB activity and FasL-induced apoptosis in primary murine hepatocytes during LPS-induced inflammation. Front Physiol. 10:117. https://doi.org/10.3389/fphys.2019.00117

56. Hayden MS, Ghosh S (2014) Regulation of NF-kappaB by TNF family cytokines. Semin Immunol. 26(3):253-266. https://doi.org/ 10.1016/j.smim.2014.05.004

57. Pugazhenthi S, Zhang Y, Bouchard R, Mahaffey G (2013) Induction of an inflammatory loop by interleukin-1beta and tumor necrosis factor-alpha involves NF-kB and STAT-1 in differentiated human neuroprogenitor cells. PLoS One. 8(7):e69585. https://doi. org/10.1371/journal.pone.0069585

58. Dalvi PS, Chalmers JA, Luo V, Han DY, Wellhauser L, Liu Y, Tran DQ, Castel J et al (2017) High fat induces acute and chronic inflammation in the hypothalamus: effect of high-fat diet, palmitate and TNF-alpha on appetite-regulating NPY neurons. Int J Obes (Lond). 41(1):149-158. https://doi.org/10.1038/ijo.2016.183

59. Jing H, Hao Y, Bi Q, Zhang J, Yang P (2015) Intra-amygdala microinjection of TNF-alpha impairs the auditory fear conditioning of rats via glutamate toxicity. Neurosci Res. 91:34-40. https://doi. org/10.1016/j.neures.2014.10.015

60. Cerami A (1992) Inflammatory cytokines. Clin Immunol Immunopathol. 62(1 Pt 2):S3-S10. https://doi.org/10.1016/00901229(92)90035-m

61. Gessi S, Borea PA, Bencivenni S, Fazzi D, Varani K, Merighi S (2016) The activation of mu-opioid receptor potentiates LPSinduced NF-kB promoting an inflammatory phenotype in microglia. FEBS Lett. 590(17):2813-2826. https://doi.org/10.1002/18733468.12313

62. Campion J, Milagro FI, Goyenechea E, Martinez JA (2009) TNFalpha promoter methylation as a predictive biomarker for weightloss response. Obesity (Silver Spring). 17(6):1293-1297. https:// doi.org/10.1038/oby.2008.679

63. Yi H, Iida T, Liu S, Ikegami D, Liu Q, Iida A, Lubarsky DA, Hao S (2017) IL-4 mediated by HSV vector suppresses morphine withdrawal response and decreases TNFalpha, NR2B, and pC/EBPbeta in the periaqueductal gray in rats. Gene Ther. 24(4):224-233. https://doi.org/10.1038/gt.2017.11

64. Ouyang H, Liu S, Zeng W, Levitt RC, Candiotti KA, Hao S (2012) An emerging new paradigm in opioid withdrawal: a critical role for glia-neuron signaling in the periaqueductal gray. ScientificWorldJournal. 2012:940613-940619. https://doi.org/10. 1100/2012/940613

65. Pardridge WM (2010) Biologic TNFalpha-inhibitors that cross the human blood-brain barrier. Bioeng Bugs. 1(4):231-234. https://doi. org/10.4161/bbug.1.4.12105

66. Chang R, Knox J, Chang J, Derbedrossian A, Vasilevko V, Cribbs D, Boado RJ, Pardridge WM et al (2017) Blood-brain barrier penetrating biologic TNF-alpha inhibitor for Alzheimer's disease. Mol Pharm. 14(7):2340-2349. https://doi.org/10.1021/acs. molpharmaceut.7b00200

Publisher's Note Springer Nature remains neutral with regard to jurisdictional claims in published maps and institutional affiliations. 